\title{
GCU
}

Glasgow Caledonian

University

University for the Common Good

\section{Influence of mouth and jaw movements on dynamics of spontaneous eye blink activity assessed during slitlamp biomicroscopy}

Doughty, Michael J.

Published in:

Clinical and Experimental Optometry

DOI:

$10.1111 / \mathrm{cxo} .12648$

Publication date:

2018

Document Version

Author accepted manuscript

Link to publication in ResearchOnline

Citation for published version (Harvard):

Doughty, MJ 2018, 'Influence of mouth and jaw movements on dynamics of spontaneous eye blink activity assessed during slitlamp biomicroscopy', Clinical and Experimental Optometry, vol. 101, no. 3, pp. 345-353. https://doi.org/10.1111/cxo.12648

\section{General rights}

Copyright and moral rights for the publications made accessible in the public portal are retained by the authors and/or other copyright owners and it is a condition of accessing publications that users recognise and abide by the legal requirements associated with these rights.

Take down policy

If you believe that this document breaches copyright please view our takedown policy at https://edshare.gcu.ac.uk/id/eprint/5179 for details of how to contact us. 


\title{
Influence of mouth and jaw movements on dynamics of spontaneous eye blink activity assessed during slitlamp biomicroscopy
}

\author{
Michael J. Doughty \\ Department of Vision Sciences, Glasgow Caledonian University, Cowcaddens Road, Glasgow \\ G4 OBA
}

Correspondence: Michael J. Doughty, E-mail address: m.doughty@gcal.ac.uk

Running head: Slitlamp based assessments of eye blink activity

\begin{abstract}
249
Background: To evaluate oculo-mandibular interactions during evaluation of spontaneous eye blink rate (SEBR) of normal young adult human subjects whilst seated at a slit-lamp

Methods: Repeat video recordings of 5 minutes duration were made on 76 young adult emmetropic subjects aged 18 to 25 years. The subjects were instructed to direct their gaze horizontally towards a distant target with the entire cornea of the left eye illuminated with a broad beam cobalt blue light. Repeat recordings were made (a) on the following day in silence in group 1, (b) immediately in silence for group 2, (c) immediately either while holding their mouth open slightly or while responding to casual conversation for groups 3 and 4 .

Results: For group 1 the averaged SEBR values for the first and second recordings were 13.5 and 14.6 blinks / min, and similar results were obtained for group 2 if the subjects were relaxed (i.e. 13.9 and 12.0 blinks / min). A slight, but statistically significant, time-related decline in SEBR was usually noted. For non-relaxed (restless) subjects exhibiting spontaneous mouth and jaw movements whilst being videographed, the averaged SEBR values were around 27 blinks / min. For groups 3 and 4, analyses of those individuals who managed to maintain a mouth open posture for the video recordings, the averaged SEBR was 7.2 blinks / min, while those engaged in casual conversation had an averaged SEBR of 20.3 blinks / min.
\end{abstract}

Conclusions: Mouth and jaw movements and a non-relaxed state can substantially affect spontaneous eye blinking

Key words: human, spontaneous eye blinks, mouth, jaw, conversation 


\section{Introduction}

The spontaneous (endogeneous) eye blink activity can be broadly considered as that which occurs without any obvious external or internal stimulation event and is an unconscious process. ${ }^{1,2}$ Over many years, investigators have noted that the eye blink activity, or more specifically the spontaneous eye blink rate (SEBR, EBR or BR), can be highly variable. A systematic review of a large number of different studies revealed average values for SEBR from any particular report ranging from 2.9 to 28.6 eye blinks / $\mathrm{min}^{2}$ Some of this variability could be entirely natural, while some of it can be attributed to the conditions under which investigators set out to measure SEBR.

One aspect of this is whether there is head and chin support (or not) during observations or recordings of SEBR. As commented upon many years ago, 'Most eye blink data have been collected in highly artificial settings with subjects placed in an apparatus to restrict head movement ...'? Some type of head / chin support has been used to facilitate eye blink recordings of subjects used for basic studies on eyelid kinematics having 'their heads maintained in a constant position', ${ }^{3}$ or 'head positioned by a modified slit-lamp stand'. ${ }^{4}$ A slitlamp head/ chin rest has been used to study lacrimal kinetics by dacryoscintigraphy with subjects asked not to blink or to 'blink normally', 5 and a slitlamp-based system has also been used for video observation of tear lipid layers in relation to eye blink activity with subjects being asked to 'blink naturally'. ${ }^{6}$ Similarly, in studies of the effect of contact lens wear on eye blink activity, subjects were positioned at slitlamp-type apparatus and asked to 'hold head and eyes steady and look straight ahead ' ${ }^{7}$ Eye blink completeness has also been qualitatively assessed while subjects were seated at slitlamp. ${ }^{8}$ In considering these experimental paradigms and based (in part) on some observations made on nominally normal healthy individuals, it has been further argued that it is also important to consider that these experimental scenarios not only have an imposed restraint on the head and jaw but also reflect a pronounced change in motor activities of a subject (in that they are no longer moving around and perhaps interacting with other people). ${ }^{9}$ Overall, the potential impact of such restraint on eye blink activity per se has received little attention in specific clinical studies. In an initial exploratory study, it was however noted that when subjects had their so called spontaneous eye blink activity assessed at the slit-lamp (i.e. with head and chin support), a small but predictable time-dependent decrease on SEBR especially over the initial minute of recording was observed. ${ }^{9}$ Such a change was not obvious if subjects were simply relaxed in a chair while SEBR was being assessed. ${ }^{2,9}$

The emphasis in this initial study on slitlamp-based assessments of SEBR (as opposed to detailed video recording of the speed of eyelid movements, for example) was to evaluate whether time-dependent changes in SEBR could occur when subjects were asked to sit quietly for a few minutes as part of relaxation period prior to assessments of their tear film. ${ }^{9}$ Further studies were considered appropriate to try to better define why some subjects showed rather higher or lower spontaneous eye blink activity when assessed with head and chin support, including consideration of the repeatability of some observed changes and of the effects of spontaneous or prompted mouth and jaw movements.

\section{Methods}

Subjects. The protocols were approved by the Life Sciences ethics committee of GlasgowCaledonian University with all investigations being conducted in accordance with the declaration of Helsinki of 1975. The subjects were simply asked whether they would be willing to participate in the author making video recordings while they sat at a slitlamp for a ' $\mathrm{few}$ ' minutes. Subject selection was based on their being between 18 and 30 years of age, in good health with no known neurological disorders, neither taking any medications that are known to substantially affect eye blink activity, pupil activity or oculomotor functions. Other exclusion 
criteria included contact lens wear, and none of the subjects were current or regular contact lens wearers. The 76 subjects who completed the studies were aged between 18 and 25 years, and were students registered in the school's optometry program, with 42 being male. All the subjects were essentially emmetropic, i.e. without any reported routine need for spectacles, and included 21 subjects reporting a manifest refractive error of - 0.5 to - $0.75 \mathrm{D}$ myopia or up to + $1 \mathrm{D}$ hyperopia.

\section{Eye blink recording methods}

All methods were essentially the same as reported previously, ${ }^{9}$ with the exception that the slitlamp was now switched on (see below), with all recordings being made between 10.30 and $16.30 \mathrm{~h}$. The subjects were first asked to complete the Glasgow-Caledonian University (GCU) Ocular Comfort Questionnaire, ${ }^{10}$ during which time they would be adapting to the examination room environment over a few minutes. The lighting (c. 350 lux), ambient temperature (range 18 to $21^{\circ} \mathrm{C}$ ), and humidity (31 to $40 \%$ ) were controlled by a central forced air circulatory system. The room was not sound-proofed but it was usually possible to maintain a reasonably quiet environment throughout the recordings (unless the examiner deliberately engaged the subjects in conversation, see later).

Eye blink recording for groups 1 and 2

In the first two studies that were designed to obtain repeat recordings either that day or on the following day, subjects (groups 1 and 2) were simply asked to sit on a comfortable seat and position themselves at the slitlamp which was switched on (at its lowest setting) as the subjects seated themselves; the slit lamp had the cobalt blue filter in place with a diffuser filter. The examiner, whilst adjusting the slit lamp height and position so that a broad beam of blue light illuminated the entire cornea of the left eye, routinely made some sort of comment like this was a 'chill-out' period, so trying to avoid the subject's being overtly aware that they were being videotaped. The camera was located, by necessity, in front of the subject at a slight angle to be able to capture a close up view of the left eye. The examiner then took a seat adjacent to the subject, just slightly behind them, at a desk on which computer linked to the video camera was set up. A verbal check was made that the subjects were comfortable and that they could see and were directing their gaze (essentially of their right eye) towards black cross target on the distant matt white-painted wall of the examination room. ${ }^{9}$ If the subject asked questions about what they were expected to do, they were given spurious answers that the examiner just wanted them to relax. They were told that the target was there so that should they (for whatever reason) decide to look elsewhere (including to perhaps see what the examiner was doing) they had been asked to try to keeping looking towards the target. No conversation took place during this period for groups 1 and 2, and the subjects were not advised as to exactly how long the video recording would be. At the end of the 5 minute recording, the subjects were advised that they could sit back and relax, and a verbal check was made on how comfortable they felt. The subjects were not advised as to the outcome of the observations made while they were seated at the slitlamp.

Based on the characteristics of their eye blink activity and with high responses given about their ocular comfort using the GCU eye comfort questionnaire, a group of the subjects (designated as group 1) were asked if they would consent to a repeat recording being made on the following day, wherein they agreed to return to following day at a similar time and repeat the assessment. On returning the following day, essentially the same protocol was followed as just outlined for the first recording. Other subjects (designated as group 2) were asked if they could be available for a repeat recording immediately. These subjects were asked to simply relax in the comfortable chair and probably watched the video recordings being saved although, as with group 1, they were not advised as to the outcome of the video recordings. Once the 
recording had been saved, the subjects were again asked to settle themselves and take their position at the slitlamp, a verbal check made for comfort and the repeat recording made.

\section{Eye blink recording in groups 3 and 4}

Two further studies were also undertaken (groups 3 and 4). These studies shared the common characteristic in that the goal was to repeat the video recordings one after the other but now with the added variables (elements) of the subjects specifically maintaining silence while holding their mouth slightly open (i.e. no mouth or jaw movements per se) and then the examiner making inter-active conversation with the subjects (where mouth and jaw movements were obviously now occurring). For group 3, a final check was made that the subjects could see the target and then they were simply quietly asked to hold their position as preparations were made to start the video. The subjects were not advised as to how long the video recording would take. The examiner was monitoring the eye blink activity and any facial or eye movements that subjects might make over this period and once they were settled, the subjects were asked to open their mouth slightly and try (as best they could) to now only breath through their mouth and the timed video was started. The subjects were quietly advised that if they needed to swallow that was acceptable, and were usually given quietly spoken words of encouragement through the video recording to maintain the slightly opened mouth posture especially after a swallowing episode. As this first 5 minute period was completed, the examiner started making a few more comments (e.g. asking how well they were doing and / or how comfortable they were) as the video file was saved. During this change-over period, the subjects were advised that they could re-adjust their position on the slit lamp if they wanted to. They were asked a range of spurious questions as the video recording was re-started, e.g. how this experience compared to their training sessions with classmates on slitlamp activity, whether they had specific interests in ocular surface health and / or how accomplished they were at the various procedures they were being taught. The level of casual conversation was deliberately kept low key, being monitored continuously by the examiner who stayed seated at the computer with his back to the subjects. The goal was essentially to make a seamless transition from recording in imposed silence without any substantial mouth movements to that whilst taking part in a conversation while still directing their gaze at the target. The repeat recording was undertaken over a 5 minute period with the examiner trying to maintain a reasonably constant casual conversation. For group 4, the procedure was reversed, i.e. the first video recording was started whilst the subjects were continuously engaged in casual conversation of a similar nature to that used for group 3 and the second period was in silence with subjects breathing through their mouth.

After all recording sessions, the subjects were advised that they could relax back in the chair and were then asked about how they felt and how challenging the task had been for them (e.g. in relation to other slitlamp experiences). Subjects, especially if they had been noted to be exhibiting higher rates of eye blink activity, were asked if they were aware of the blue light on their eyes. They were also asked how challenging the mouth open posture was for them and also if they now had a dry mouth. Most subjects also completed the GCU Ocular Comfort Questionnaire VAS assessment for a second time without being allowed to see what they had reported prior to the slitlamp-based assessment of their eye blink activity.

\section{Evaluation of eye blink recordings}

The video recordings were assessed by the investigator using the software as included in the camera operations system. The procedure followed by the author was to simply replay the recording and manually count the number of blinks in each successive minute, replaying sections of the recording if there was any uncertainty. ${ }^{9,11,12}$ 


\section{Statistical analyses}

The minimum size of the groups ( $n=15$ ) was selected on the basis of the expected variability in SEBR for carefully selected normal adult subjects, with an $80 \%$ power to detect a difference the same as the expected standard deviation in SEBR (i.e. c. 3 eye blinks / min). This would be expected for subjects showing normal eye blink activity while silently seated in a chair with a head back support and in primary eye gaze to a distant target without any visual glare, ${ }^{11,12}$ or, for the most part, when being evaluated at a slitlamp. ${ }^{9}$ All data were entered into spreadsheets in Systat v. 11 (Systat, Evanston, IL) to generate global statistics and graphical outputs. The normality of all data sets was checked using the default Shapiro-Wilk statistic as incorporated in Systat. The number of eye blinks in any one minute period was counted (and global mean values also calculated for sets of subjects) and, in addition, the averaged SEBR ( \pm SD) over 5 minutes also calculated along with the coefficient of variation (COV) on this averaged value. ${ }^{9}$ For most comparisons, a Friedman ANOVA was used to assess if minute-by-minute differences in means or averaged SEBR values were detectable, and a simple linear model regression analysis was used to assess time-related changes over the 5 minute recording periods. In all cases, the level of statistical significance was set at $\mathrm{p}=0.05$.

\section{RESULTS}

Overall characteristics of the spontaneous eye blink activity at the slit lamp and its assessment The 76 subjects who successfully completed both recordings were considered normal and healthy. None of the subjects indicated any notable ocular discomfort prior to the assessments, with the average comfort score (VAS) being $92 \pm 7$ (range 84 to 99). Essentially the same results were obtained after the slitlamp-based assessments of their eye blink activity. An eye blink event was considered to have taken place if there was an obvious downward movement of the upper eyelid, extending to at least half closure (and covering the pupil) and usually what appeared to be to a complete closure. Any slight twitches of the upper eyelid were ignored. Occasionally a subject, regardless of whether silent or engaged in conversation, showed an isolated slow or prolonged eyelid closure event that could last up to $0.4 \mathrm{~s}$ and was usually complete. Since the subjects were being asked to essentially adopt an unnatural position of being asked to sit behind a slitlamp for a few minutes, particular attention was paid to the overall posture of the subjects and as to whether they were showing outward signs of being comfortable as opposed to slightly moving their head and or jaw repeatedly.

\section{Group 1 : Repeatability of SEBR at the slit lamp as assessed in silence and relaxed on consecutive days}

In Figure 1A is shown the outcome of the SEBR recordings for 16 individuals at the first assessment and then in Figure $1 \mathrm{~B}$ as at the re-assessment on the following day. In this study (group 1), the subjects were selected because they seemed to be relaxed and comfortable and did not appear to have any notable problems in maintaining a quiet posture at the slitlamp for 5 minutes. Initially, 20 subjects were actually successfully videographed for the first session, but 4 of them failed to return within an hour or so of their original recording time on the following day so they were not re-evaluated. The averaged SEBR (over 5 minutes) in the first recording was $13.5 \pm 3.8$ eye blinks / $\min (n=16)$ and was $14.6 \pm 2.7$ eye blinks / min over the repeat recording. These averaged SEBR values ranged from 7.4 to 19.6 / min on the first recording and from 11.8 to 20.8 / $\mathrm{min}$ in the repeat with no difference detectable in the averaged SEBR between the two recordings $(\mathrm{p}=0.408)$. Most subjects $(14 / 16)$ consistently showed SEBR values in any particular minute that were within a normally-expected range (and being less than $21 / \mathrm{min}$ ), but 2 subjects showed much higher SEBR values (of up to 40 / min) in one or two of the minute 
periods even though their overall averaged SEBR was still below 21 / min. Nothing really untoward seemed to be evident on the video recordings, although one of the latter subjects seemed to be rather restless on both occasions (see next section). Overall, the minute-by-minute variability in SEBR (calculated as the COV of the averaged value), while it showed a trend to decline over time, averaged $27.1 \%$ in the first recording and $28.8 \%$ in the second.

Overall, for the initial recording, there was a very obvious time-related reduction in SEBR over the 5 minutes with the mean SEBR in the first minute being $16.1 \pm 8.3$ / min and just $10.3 \pm 2.7 /$ min for the $5^{\text {th }}$ minute ( $p<0.036$ comparing minute 5 versus minute 1$)$. Regression analysis indicated a predictable time-related decrease $(\mathrm{p}=0.023, \mathrm{r}=0.928)$. On the repeat recording (on the following day), this time-related change was again seen, but was slightly less pronounced (Figure 1B). The mean SEBR for the first minute was $16.3 \pm 6.2$ eye blinks / min and was $12.9 \pm 2.5$ eye blinks / min over the $5^{\text {th }}$ minute, with this change again being statistically different $(\mathrm{p}=0.007)$. However, a detectable time-related reduction in SEBR by regression analysis just failed to reach statistical significance $(\mathrm{p}=0.091, \mathrm{r}=0.081)$.

Group 2: Repeatability of SEBR at the slit lamp within a few minutes as assessed in silence A second group of 30 subjects all agreed to undertake a repeat recording within a few minutes of the first one. The overall results are shown in Figure 2.

The averaged SEBR over the first recording was $17.8 \pm 6.7 / \mathrm{min}$ and $16.7 \pm 8.1 / \mathrm{min}$ in the repeat recording. Both these sets of recordings for group 2 were notably different from those in the first set of repeat experiments (i.e. group 1) in that the averaged SEBR was higher $(\mathrm{p}<$ 0.05 ) and, as is hopefully evident in the figure, showed notably greater inter-subject variability. For completeness, it can be noted that there was no detectable time-related change in the SEBR values in either the first or second recordings $(p \geq 0.2)$ for group 2 subjects.

Examination of the videos of this group of subjects revealed that 6 of them (3 males, 3 females) exhibited obvious signs of difficulty in relaxing at the slitlamp, especially while the second video recording was being made. As part of what was considered to be signs of the subjects being restless, they exhibited repeated small head movements (against the forehead support) and notable jaw movements (against the chin rest) during the video recordings. In addition they exhibited what was considered to be anomalous 'frequent eye blink' activity in that their SEBR values were quite often well above $40 \mathrm{~min}$ (see below). The data from the subjects in group 2 were therefore re-analysed according to whether they appeared to be relaxed or restless. For the 24 subjects who managed to sit quietly throughout both recordings, their data was found to be very similar to that in group 1 (compare Figures 3 and 1), while the restless subjects clearly had a very different time-related profile for their spontaneous eye blink activity (Figure 4).

Overall, for those able to relax at the slitlamp for two video recordings, their averaged SEBR (over $5 \mathrm{~min}$ ) was $13.9 \pm 3.2$ / $\mathrm{min}$ in the first video (with a COV of $27.5 \%$ ) and slightly lower at $12.0 \pm 1.7$ / min (with a COV of $20.1 \%$ ) in the repeat recording. Overall, in this subgroup only 2 subjects showed any SEBR values higher than 21 / min in any particular one minute period of observation (and only in a total of four such periods), and did not show these again in the repeat recording. SEBR data from the initial minute of the first recording was $16.0 \pm$ $7.6 / \mathrm{min}$ and declined to $11.2 \pm 3.6 / \mathrm{min}$ by the $5^{\text {th }}$ minute. This gave a net difference of nearly four blinks / $\min (\mathrm{p}<0.001)$, with there being an obvious time-related reduction in SEBR values (Figure 3A) that was statistically significant $(p=0.035, r=0.904)$. For the repeat recording (made essentially immediately after the first), these relaxed subjects showed a stable SEBR profile over the 5 minutes (Figure 3B). The mean SEBR in the first minute (at $12.9 \pm 4.3 / \mathrm{min}$ ) was not significantly different from that in the $5^{\text {th }}$ minute (at $12.1 \pm$, $3.3 / \mathrm{min} ; \mathrm{p}>0.5$ ) and no detectable time-related trend in SEBR was evident $(\mathrm{p}=0.318, \mathrm{r}=0.5687)$. 
Analysis of those subjects considered to be restless, and showing mouth and jaw movements while positioned at the slitlamp during the videorecording, is given in Figure 4. Overall, their averaged SEBR in the first recording period was $27.0 \pm 2.7 / \mathrm{min}$ and $27.7 \pm 6.8$ / min for the repeat. Of all the one minute periods during the two sets of recordings for these restless subjects, SEBR values below 21 / min were only seen in 9/ 60, i.e. in most one minute intervals the SEBR values were consistently above 21 / $\mathrm{min}$ and as high as 46 / $\mathrm{min}$. There were no detectable changes in SEBR over time $(p \geq 0.5)$.

\section{Groups 3 and 4: Repeatability of SEBR measures at the slitlamp without mouth movements and in conversation}

Based on some initial observations, especially with group 2, a further set of experiments were developed to specifically examine the potential impact of intentional mouth and jaw movements (induced by conversational responses) on SEBR versus a deliberate strategy to try to prevent such movements (by a mouth-open paradigm). The subjects were not specifically informed that these variables would be part of the assessment, and the examiner made an arbitrary choice on the order of the protocol to be followed. The subjects were given no cues as to how they might respond to the questions. A total of 33 subjects were initially recorded but 3 of them showed evidence of being restless especially during the mouth open recordings and so were excluded from further detailed analyses (but showed overall characteristics similar to those shown in Figure 4). Overall, therefore an equal number of 15 subjects each were successfully videographed in two groups, the first being initially with the open mouth posture and then in conversation, and the second initially in conversation and then with the open mouth posture. The results can be considered both in terms of a first versus a second recording in terms of repeatability (Figure 5), as well as according to whether the subjects maintained silence without mouth movements (Figure 6A) or were in conversation (Figure 6B).

For the initial recording period, with some subjects in silence and the others in conversation, there was no detectable change in the measured SEBR over 5 minutes (Figure 5A), and with little indication of any time-related change in average SEBR over the second period of recording (Figure 5B). For the initial period, the SEBR averaged $12.9 \pm 6.1 / \mathrm{min}$ (range 4.0 to 26.4 / $\mathrm{min}$ ), and while the overall minute-by-minute variability (as COV) was $28.5 \%$ it was clearly increasing over time (with increasing SD values). No time-related change in SEBR could be detected $(p=0.104)$. The same applied to the second period of recording (Figure 5B) with no time-related change $(\mathrm{p}=0.522)$, the overall COV being higher at $32.5 \%$ and increasing with time. Overall, the mean SEBR in the second period was slightly higher than the first period (14.6 \pm 8.3 / min, range 3.6 to 25.6 / $\mathrm{min}$ ) but the difference was not significant ( $\mathrm{p}=0.592$ ). As with the earlier analyses of a heterogeneous data set (Figure 2), there was a notable magnitude to the inter-subject variability.

If the recording was made with the subjects holding their mouth slightly open then, even within 1 minute, this small change in posture resulted in a detectable reduction in SEBR with an average of $11.1 \pm 3.2$ / min (range 5.0 to 18.0 / $\mathrm{min}$ ). There were similar progressive reductions in SEBR over each successive minute (Figure 6A) to realize a mean value of just $4.1 \pm 1.8$ / min over the 5th minute ( $\mathrm{p}<0.001$; range of average SEBR values from 1.0 to $8.0 / \mathrm{min}$ ). A timerelated analysis, by regression, confirmed this change $(\mathrm{p}=0.005, \mathrm{r}=0.973)$. As examined on a minute-by-minute basis, there was a slight but progressive reduction in the inter-subject variability in SEBR (with smaller and smaller SD values). Over the 5 minutes, the SEBR was 7.2 \pm 1.8 / min (range of average values of 3.6 to $11.0 / \mathrm{min}$ ) which was statistically lower than the recordings simply made in silence $(\mathrm{p}<0.001)$. Overall, the SEBR variability, as COV, was substantially higher at $\mathbf{4 1 . 0} \%$ partly because of some subjects had both slightly higher and much lower SEBR values in different 1 minute periods. 
However, if the subjects had been engaged in conversation from the start of the video recording, a progressive increase in SEBR occurred (Figure 6B). Overall, the magnitude of this change during ongoing conversation over 5 minutes was slightly less than if the no jaw movement paradigm was adopted (i.e. Figure 6A). Notwithstanding, the SEBR in the initial minute of conversation was still detectably higher than for subjects in silence (with a mean value of $17.0 \pm 5.4$ / $\mathrm{min}$, range 7.0 to 27.0 / $\mathrm{min}$ ), higher again for the second minute (mean $18.9 \pm 5.7$ / min, range 7.0 to $29.0 / \mathrm{min}$ ) and realized a mean of $23.5 \pm 5.1 / \mathrm{min}$ (range 13.0 to 32.0 / min) by the $5^{\text {th }}$ minute of recording. Over the 5 minutes, the overall mean SEBR under conversation was $20.3 \pm 3.7$ / min, a value that was statistically higher than recordings made in silence over the same time period $(\mathrm{p}<0.001)$. The difference between the first and 2nd minute was significant $(\mathrm{p}=0.043)$ as was that in the $5^{\text {th }}$ minute $(\mathrm{p}<0.001)$, and regression analyses confirmed this time-related increase ( $\mathrm{p}<0.001, \mathrm{r}=0.998)$. The overall variability in SEBR over the 5 minute period during conversation was $20.1 \%$, but when assessed on a minute-by-minute basis there was an obviously large inter-subject variability (with relatively large SD values) (Figure 6B).

Overall, all subjects in groups 3 and 4 completed the recordings without incident. For the mouth open paradigm, most subjects (23 / 30) did indicate it was challenging and that they did have a slightly dry mouth after the 5 minutes. Overall, no obvious changes in eye blink activity were noted during any brief episodes of swallowing that routinely occurred during imposition of this paradigm. None of the subjects seemed to have any difficulty in engaging in conversation (probably because they knew the examiner) and although some only gave very cursory responses at times, most responded with a sentence or two whilst still maintaining their position at the slitlamp. For just 2 subjects, some effort was sometimes needed (on the part of the examiner) to keep the subjects from getting too responsive and animated because of the associated head movements that then started to occur (including brief loss of contact with the forehead support ring).

\section{Discussion}

The present studies were initially planned as simply a more substantial investigation of slitlampbased assessment of SEBR conducted in an initial exploratory study. ${ }^{9}$ The results however reveal some very notable characteristics of spontaneous eye blink activity that have not received much consideration, especially within the context of using SEBR as a physiological measure. Overall, it may not be a given that subjects can 'blink normally' when seated at a slitlamp. Systematic investigations on the consequences of a conscious effort to stop mouth or jaw movements on the so-called spontaneous eye blink activity do not appear to have been previously undertaken. However, the results obtained essentially confirm a miscellany of previous observations in that eye blink activity can be linked to mouth and jaw movements. ${ }^{13-23}$

None of the subjects evaluated in the present study had any known neuromuscular disorders. However, it has been noted that, for example, movements of jaw muscles (without talking, but with chin rest used) can affect the eyelid levator muscle EOG activity, ${ }^{13}$ or that jawwink phenomena can involve involuntary relief of ptosis associated with various jaw movements. ${ }^{14}$ It has also been proposed that such intermittent retraction of a ptotic lid while chewing or otherwise moving the jaw could be due to 'presumed miswiring between ocular motor and trigeminal motor pathways', ${ }^{15}$ including in specific disorders such as Meige's syndrome. ${ }^{16}$ Similarly, it has been noted that there could be links between the eye blink reflex and jaw-stretch reflex, ${ }^{17}$ with jaw and blink reflexes coupled to the trigeminal system. ${ }^{18}$ Synchronization of orbicularis oculi and orbicularis oris responses to electrical stimulation can occur, ${ }^{19}$ with such interactions between these muscle group activities occurring because of some 
common innervation pathways. ${ }^{20-22}$ Jaw jerk reflex to chin taps can be correlated with blink reflex to glabella taps. ${ }^{23}$

The opposite scenario is much less predictable and unscheduled (and uncontrolled) mouth and jaw movements associated with ongoing conversation during observations of eye blink activity. Activation of cortical speech motor centers which are close to those which control the eyes could result in overflow into oculo-motor control areas and so resulting in increases in blink rate; ${ }^{1,24}$ it has subsequently been well established that subjects engaged in conversation are likely to show higher SEBR values. ${ }^{2,11,25}$ A systematic literature review based on numerous studies established that SEBR rates during conversation were predictably higher. ${ }^{2}$ At that time, studies also indicated that the enhanced SEBR reflected, in part, the extent of interaction (engagement) of a subject during conversation, ${ }^{2}$ and so cognitive processes (rather than just jaw movements) appear to be involved. In more recent assessments of such interactions, eye blink frequencies (as blinks /s) were observed to fluctuate substantially according to whether subjects were listening, reading or in conversational responses. ${ }^{25}$ In specific early studies using EOG methods, Karson and colleagues ${ }^{26}$ reported that blink rates increased when subjects were speaking as opposed to sitting in silence, but that both reading outloud as well as thinking about a particular problem (the significance of proverbs) also increased eye blink rates. It was also concluded in these early studies that the eye blink rates appeared to be unaffected by mouth and jaw movements per se in that the SEBR was the same for the subjects sitting in silence (and presumably showing minimal mouth and jaw movements) and those who were asked to chew gum while their eye blinks were being discretely assessed. ${ }^{26}$ No obvious attempt was made to assess whether the frequency of mouth movements during talking could be connected to SEBR. Normal speech rates have been reported to be around 130 words / $\mathrm{min} .{ }^{27}$ When reading outloud in SEBR studies, average reading rates at least 100 words /min and perhaps as high as 200 words / min have been reported, ${ }^{28}$ but detailed analyses of actual mouth movements were not provided (with the incidence of these being expected to be much higher for complex words).

The adoption of the mouth open posture (along with deliberate mouth, rather than nasal breathing) was, in part, prompted from two contrasting observations. In studies made on other individuals, some were seen to actually open their mouth periodically (and even hold it open) during slitlamp video recordings of the tear meniscus. From the opposite perspective, some subjects (also involved in other studies) displayed obvious and repeated jaw movements (usually from side-to-side) while they sat at the slit lamp. In the present study, when such individuals were asked why they were exhibiting repeated jaw movements and whether it was because they were uncomfortable, none provided a clear answer and, quite often, were simply not aware that they were doing this. The present studies indicate that such individuals could also be regarded as being restless, although the hyperactivity of spontaneous jaw movements was not noted in previous studies on subjects simply being asked to relax in a comfortable chair rather than being assessed at the slitlamp. ${ }^{29}$ On being questioned, none of the subjects in the present slitlamp-based assessments acknowledged feeling 'restless' nor were they aware (until later shown their videos) that they were clearly not sitting 'quietly' at the slitlamp.

Overall, therefore, the selection of the 'hold mouth open' experimental paradigm seemed a logical approach to assessing whether a deliberate attempt to minimize mouth and jaw movements would have a measurable impact on SEBR assessments. Preliminary results from a small group (9) of older subjects (aged 42 to 65 years) indicate the same phenomenon occurs, i.e. a markedly reduced SEBR. At the present time, a definitive statement cannot be given as to why this mouth open posture reduced SEBR. As indicated earlier, that such an effect can be readily observed is consistent with there being co-activation (or suppression in this case) of neurological pathways involving the two muscle groups of the eyelids and jaw. However, the posture could 
also be associated with an unconscious response related to visual demand to facilitate better concentration.

The occurrence of frequent eye blink activity during the slitlamp-based videorecording of spontaneous eye blink activity was not obviously linked to any form of ocular discomfort as high comfort scores were reported by all subjects before and after the recordings. In addition, the author routinely took a few moments to set up the slit lamp and at the same time undertake a cursory examination of the external eye to assess normality. None of subjects showed any obvious abnormalities, especially with respect to eyelid margins for any signs of inflammation etc., and the large variability in SEBR sometimes observed was not obviously related to the extent of ocular cosmetics use. No specific assessments of tear film abnormalities (e.g. tear film break up time) were undertaken however in these studies and could be useful.

Overall, the results from the present sets of first recordings (i.e. Figures 1 and 3) are consistent with those overall rates of SEBR values over 5 minutes previously reported under what might be termed 'neutral' conditions for subjects adopting a primary eye gaze in silence. .,30 $^{2}$ Based on a literature analysis, the SEBR in primary eye gaze and in silence should have reasonably averaged predictable values, e.g. estimated to be around 14.5 blinks / min and with a predictable range from 8.5 to 21 eye blinks/ min (based on $95 \%$ confidence interval or CI calculated from \pm 1.96 SD of the group mean value). ${ }^{2}$ For slitlamp-based assessments of SEBR, the present studies on relaxed subjects, as well as equivalent subjects in the exploratory study, ${ }^{9}$ indicate similar averaged SEBR values over $5 \mathrm{~min}$, e.g. group averages of 13.5 and 13.9 /min for the first recordings in silence in the present study, and $13.9 / \mathrm{min}$ in the previous study. ${ }^{9}$ However, in marked contrast, the averaged SEBR values for non-relaxed subjects were close to 27 / min.

The present studies confirm observations made in an earlier study, ${ }^{9}$ in that a small but significant time-dependent decline in SEBR may not be unusual in slitlamp-based assessments of SEBR for subjects in primary eye gaze and in silence. The subject preparation and the experimental set up was essentially the same in both studies except that, for the present study, the slitlamp was switched on. It was not switched on in the previous study, ${ }^{9}$ to avoid any possibility that the so-called spontaneous eye blink activity could be influenced by a blue light stimulus. In the present study, almost half the subjects (34 / 76) indicated that they were aware of the blue light from the slit lamp, but that it did not bother them. In separate experiments, assessments have been made to see whether or not the illumination or non-illumination of the ocular surface with the slitlamp beam produced any discernable eye blink response. This was done by simply moving the slit lamp to one side as the recording was being made and then moving it back again, with this being repeated several times over a minute or so. In no instances, in over 50 trials on 10 different subjects from the present study (aged between 19 and 64 years), was an obvious eye blink event seen that was obviously associated with either illumination or moving the slitlamp beam away from the left eye (unpublished data). With the averaged SEBR values over 5 minutes (at least for a first recording) being essentially the same regardless of whether the eye was illuminated with blue light or not further argues against there being a notable influence of the blue light.

Overall, the frequency at which a decline in SEBR might occur during slitlamp-based assessments of SEBR requires further study, but the consequence of not having a predictable 'stable' eye blink rate in this commonly-used experimental set up needs to be addressed. For what were designated as relaxed subjects, this time-related decline appeared to be slightly different according to whether assessments were repeated immediately (Figure 3) or on the following day (Figure 1). The less obvious time-related decline in SEBR indicates short-term adjustment or that adaptation to the 'unnatural' posture of the slitlamp-based assessment may be lost when repeats are made the following day. If a lesser decline had been seen in both repeat 
assessments, this might be referred to as some type of 'learning' effect but this was not seen. It should be again noted that numerous repeat assessments of SEBR for subjects simply sitting in a chair have not shown such time-related declines. As indicated previously, ${ }^{9}$ in any further SEBR assessments using subjects with head and chin support more attention could usefully be given to reporting on any time-related changes.

\section{Acknowledgements}

No specific funding or grants were needed for this study. The author declares no proprietary interests in any of the protocols or instrumentation used.

\section{References}

1. Stern JA, Walrath LC, Goldstein R. The endogenous eyeblink. Psychophysiol 1984; 21: 22-33.

2. Doughty MJ. In consideration of three types of spontaneous eyeblink activity in normal humans - during reading and VDT use, in primary gaze and while in conversation. Optom Vis Sci 2001; 78: 712-725.

3. Evinger C, Manning KA, Sibony PA. Eyelid movements. Mechanisms and normal data. Invest Ophthalmol Visual Sci 1991; 32: 387-400.

4. Doane MG. Interaction of eyelids and tears in corneal wetting and the dynamics of the normal human eyeblink. Am J Ophthalmol 1980; 89: 507-516.

5. White WL, Glover T, Bucker AB. Effect of blinking on tear elimination as evaluated by dacryscintigraphy. Ophthalmology 1991; 98: 367-369.

6. Korb DR, Baron DF, Herman JP, Finnemore VM, Exford JM, Hermosa JL, Leahy CD, Glonek T, Greiner JV. Tear film lipid layer thickness as a function of blinking. Cornea 1994; 13: 354-359.

7. Brown M, Chinn S, Fatt I, Harris MG. The effect of soft and hard contact lenses on blink rate, amplitude and length. J Am Optom Assoc 1973; 44: 254-257.

8. Gauba V, Curtis ZJ. Sleep position and the ocular surface in a high airflow environment. Saudi J Ophthalmol 2014; 28: 66-68.

9. Doughty MJ. Assessment of short term variability in human spontaneous eyeblink rate during video observation with or without head / chin support. Clin Exptl Optom 2016; 99: 135-141.

10. Doughty MJ, Lee C-A, Ritchie S, Naase T. An assessment of the discomfort associated with the use of rose bengal $1 \%$ eyedrops on the normal human eye - a comparison with saline 0.9 $\%$ and a topical ocular anaesthetic. Ophthal Physiol Opt 2007; 27: 159-167.

11. Doughty MJ. Effects of background lighting and retinal illuminance on spontaneous eyeblink activity of human subjects in primary eye gaze. Eye Contact Lens 2013; 39: 138-146.

12. Doughty MJ. Spontaneous eyeblink activity under different conditions of gaze (eye position) and visual glare. Graefe's Archiv Clin Exptl Ophthalmol 2014; 252: 1147-1153.

13. Liang H, Song J, Shen D, Qiao Y, Zhang J. Co-firing of levator palpebrae and masseter muscles links the masticatory and oculomotor system in humans. J Biomed Res 2015; 29: 316320.

14. Sundareswaran S, Nipun CA, Kumar V () Jaw-winking phenomenon: Report of a case with review of the literature. Indian J Dental Res 2015; 26: 320-323.

15. Wong JF, Therialt JF, Bouzouaya C, Codere F. Marcus Gunn jaw-winking phenomenon: a new supplemental test the preoperative evaluation. Ophthal Plast Reconstruct Surg 2001; 17: 412-418.

16. Mascia MM, Valls-Solé J, Martí MJ, Sanz S. Chewing pattern in patients with Meige’s syndrome. Movement Disorders 2005; 20: 26-33.

17. Peddireddy A, Wang K, Svensson P, Arendt-Nielsen L () Influence of age and gender on the jaw-stretch and blink reflexes. Exp Brain Res 2006; 171: 530-540. 
18. Sanders EACM, Ongerboer de Visser BW, Barendswaard EC. Jaw, blink and corneal reflex latencies in multiple sclerosis. J Neurol Nueorsurg Psychiatry 1985; 48: 1284-1289.

19. Choi SI, Kim M-W, Park DY, Huh R, Jang D-H. Electrophysiologic investigation during facial motor neuron suppression in patients with hemifacial spasm: Possible pathophysiology of hemifacial spasm: A pilot study. Ann Rehabil Med 2013; 37: 839-847.

20. Esteban A, Traba A, Prieto J. Eyelid movements in health and disease. The supranuclear impairment of the palpebral motility. Neurophysiologie Clinique 2004; 34: 3-15.

21. Hanakawa T, Dimyan MA, Hallett M. The representation of blinking movement in cingulate motor areas: A functional magnetic resonance imaging study. Cerebral Cortex 2008; 18: 930-937.

22. Cattaneo L, Pavesi G. The facial motor system. Neurosci Behavioural Rev 2014; 38: 135159.

23. Widmalm SE () Long latency components of the jaw jerk and blink reflex in man. $J$ Oral Rehabil 1982; 9: 479-486.

24. Meyer DR. On the interaction of simultaneous responses. Psychological Bull 1953; 50: 204220.

25. Bailly G, Raidt S, Elisei F. Gaze, conversational agents and face-to-face communication. Speech Communication 2101; 52: 598-612.

26. Karson CN, Berman KF, Donnelly EF, Mendelson WB, Kleinman JE, Wyatt RJ. Speaking, thinking, and blinking. Psychiat. Res 1981; 5: 243-246.

27. Fernández-Lansac V, Crespo M. Narrative length and speech rate in battered women. PLOS One 2015; 10: e0142651.

28. Ousler GW, Rodriguez JD, Smith LM, Lane KJ, Heckley C, Angjeli E, Abelson MB. Optimizing reading tests for dry eye disease. Cornea 2015; 34: 917-921.

29. Doughty MJ, Naase T. Further analysis of the human spontaneous eyeblink rate by a clusteranalysis-based approach, to categorise individuals with 'normal' versus ' frequent' eyeblink activity. Eye Contact Lens 2006; 32: 294-299.

30. Zaman ML, Doughty MJ. Some methodological issues in the assessment of the spontaneous eyeblink in man. Ophthal Physiol Opt 1997; 17: 421-432. 
TABLE 1 SUMMARY DATA FOR SPONTANEOUS EYE BLINK ASSESSMENTS

\begin{tabular}{|l|l|l|l|l|}
\hline SUBJECT GROUP & $\begin{array}{l}\text { NUMBER } \\
\text { OF } \\
\text { SUBJECTS }\end{array}$ & $\begin{array}{l}\text { SEBR OVER } \\
\text { 5 MINUTES } \\
\text { ON FIRST } \\
\text { RECORDING } \\
\text { (EYE BLINKS / MIN, } \\
\pm \text { SD) }\end{array}$ & $\begin{array}{l}\text { SEBR OVER } \\
\text { 5 MINUTES } \\
\text { ON SECOND } \\
\text { RECORDING } \\
\text { (EYE BLINKS / MIN, } \\
\pm \text { SD) }\end{array}$ & $\begin{array}{l}\text { NOTES on SEBR } \\
\text { TIME-RELATED } \\
\text { FEATURES }\end{array}$ \\
\hline Group 1 & 16 & $14.6 \pm 2.7$ & $\begin{array}{l}\text { Time-related decline } \\
\text { in both recordings }\end{array}$ \\
\hline Group 2 (all) & 30 & $17.8 \pm 6.7$ & $\begin{array}{l}\text { Slight time-related } \\
\text { decline in both } \\
\text { recordings }\end{array}$ \\
\hline Group 2 - relaxed & 24 & $13.9 \pm 3.2$ & $\begin{array}{l}\text { Time related decline, } \\
\text { especially for first } \\
\text { recording }\end{array}$ \\
\hline $\begin{array}{l}\text { Group 2 - non-relaxed } \\
\text { and showing jaw } \\
\text { movements) }\end{array}$ & 6 & $27.0 \pm 2.7$ & $\begin{array}{l}\text { No obvious time-related } \\
\text { decline in either } \\
\text { recording }\end{array}$ \\
\hline Groups 3 and 4 (all) & 30 & $12.9 \pm 6.1$ & $\begin{array}{l}\text { No obvious time-related } \\
\text { decline in either } \\
\text { recording }\end{array}$ \\
\hline $\begin{array}{l}\text { Group 3 - mouth open } \\
\text { Group 4 - conversation }\end{array}$ & 15 & $7.7 \pm 1.8$ & $\begin{array}{l}\text { Time-related } \\
\text { decline in SEBR in } \\
\text { both recordings }\end{array}$ \\
\hline
\end{tabular}




\section{FIGURE CAPTIONS}

Figure 1. Time dependent assessment of spontaneous eye blink rate (SEBR) while seated at a slitlamp for 16 subjects (group 1 ) at a first recording (A), and at a second recording repeated at a similar time the following day (B). Each data point represents mean \pm SD.

Figure 2. Time dependent assessment of spontaneous eye blink rate (SEBR) while seated at a slitlamp for 30 subjects (group 2) at a first recording (A), and at a second recording repeated almost immediately (B). Each data point represents mean \pm SD.

Figure 3. Time dependent assessment of spontaneous eye blink rate (SEBR) while seated at a slitlamp over a first recording (A) and at a second recording repeated almost immediately (B) for 24 subjects considered to be relaxed. Each data point represents mean \pm SD.

Figure 4. Time dependent assessment of spontaneous eye blink rate (SEBR) while seated at a slitlamp over a first recording (A) and at a second recording repeated almost immediately (B) for 6 subjects considered to be non-relaxed (restless). Each data point represents mean \pm SD.

Figure 5. Time dependent assessment of spontaneous eye blink rate (SEBR) while seated at a slitlamp for 30 subjects (groups 3 and 4) at a first recording (A), and at a second recording repeated immediately (B). Each data point represents mean \pm SD.

Figure 6. Time dependent assessment of spontaneous eye blink rate (SEBR) while seated at a slitlamp for 30 subjects according to whether they were maintaining a mouth open posture (A), or engaged in casual conversation (B). Each data point represents mean \pm SD. 

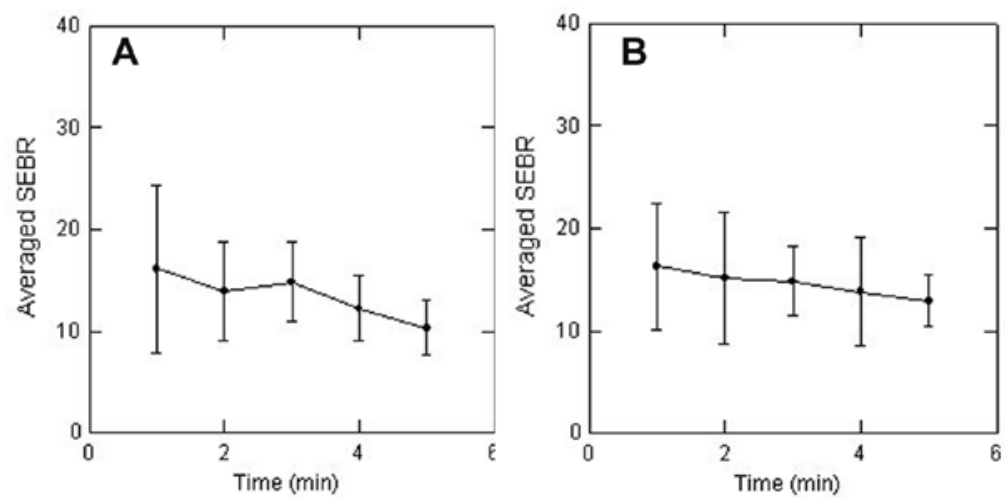

FIGURE 1
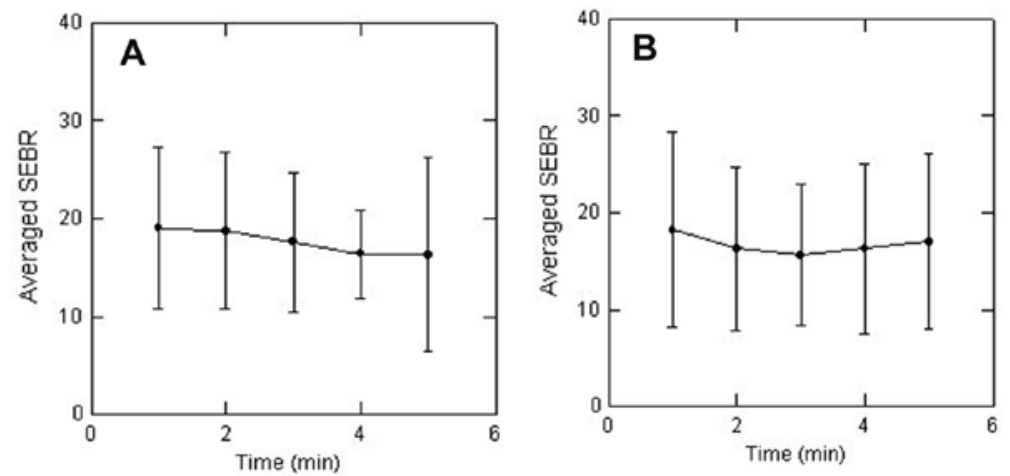

FIGURE 2
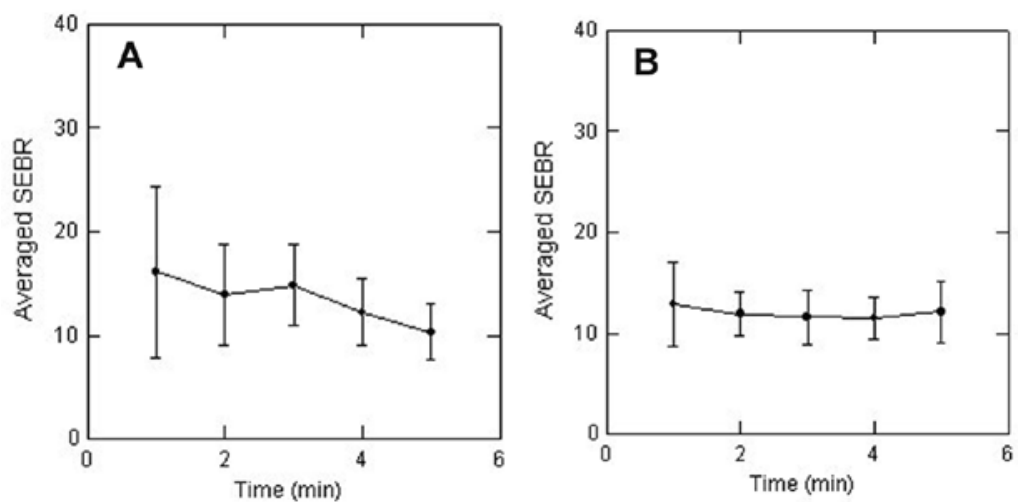

FIGURE 3 

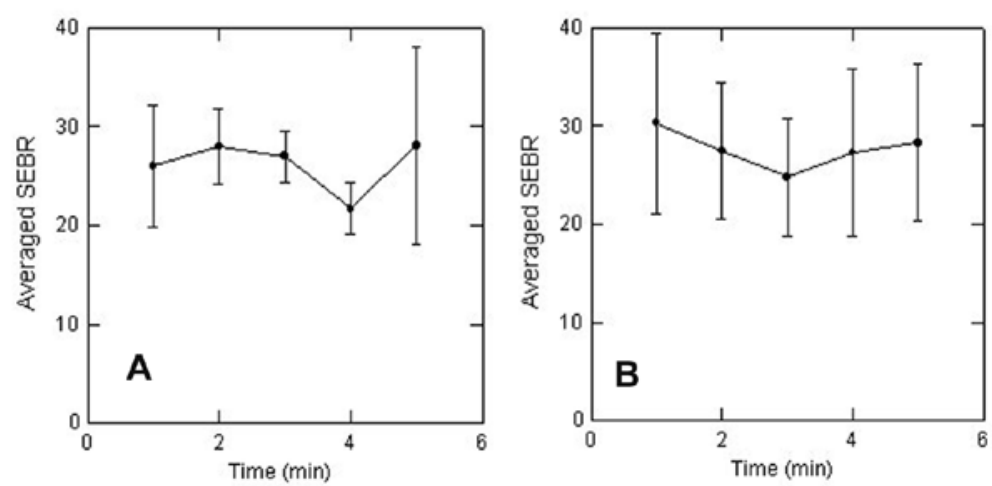

FIGURE 4
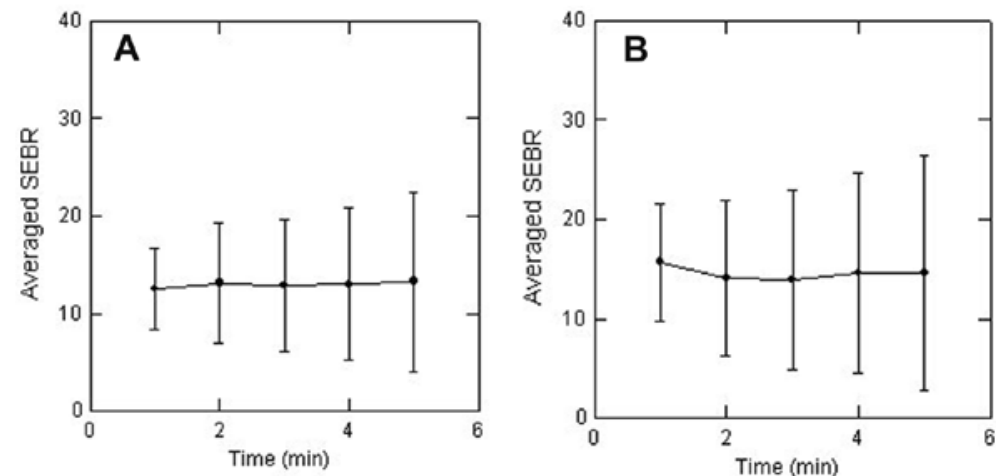

FIGURE 5
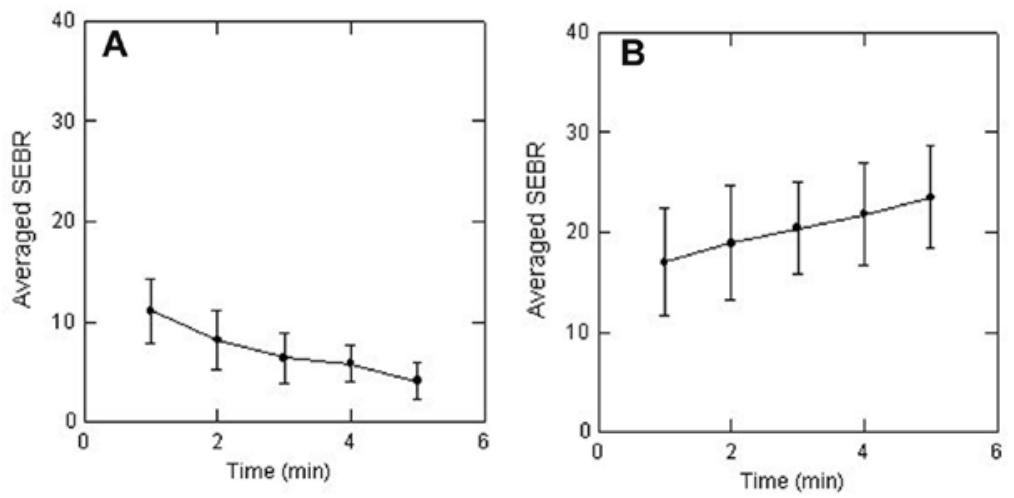

FIGURE 6 